\title{
Genome Sequence Resource for Colletotrichum scovillei, the Cause of Anthracnose Disease of Chili
}

\author{
Jianfei Huo, ${ }^{1}$ Yafei Wang, ${ }^{2}$ Yongjuan Hao, ${ }^{1}$ Yurong Yao, ${ }^{1}$ Yong Wang, ${ }^{1}$ Kai Zhang, ${ }^{2}$ Xinqiu Tan, ${ }^{3}$ \\ Zhiqiang $\mathrm{Li}^{2, \dagger}$ and Wanli Wang ${ }^{1, \dagger}$ \\ ${ }^{1}$ Institute of Plant Protection, Tianjin Academy of Agricultural Sciences, 300381 Tianjin, China \\ ${ }^{2}$ State Key Laboratory for Biology of Plant Diseases and Insect Pests, Institute of Plant Protection, \\ Chinese Academy of Agricultural Sciences, 100193 Beijing, China \\ ${ }^{3}$ Institute of Plant Protection, Hunan Academy of Agricultural Sciences, 410125 Changsha, Hunan \\ Province, China
}

\begin{abstract}
Colletotrichum species cause anthracnose disease on the economically important spice crop chili. A total of 24 Colletotrichum species are known to infect chili and cause anthracnose. $C$. scovilleibelongs to the $C$. acutatum species complex, and it shows greater aggressiveness than other species, particularly in the case of inoculation onto the nonwounded fruits of chili plants. The current work introduces an initial Illumina-Nanopore hybrid draft genome for C. scovillei TJNH1 together with the related annotations. Knowledge of this genome sequence provides an important reference genome of $C$. scovillei and will help further understand the pathogenic mechanism of $C$. scovillei to plant.
\end{abstract}

\section{Genome Announcement}

Chili is one of the widely consumed crops in the world. Anthracnose is a severe disease of chili affecting both fruit and seed quality. It can cause serious damage to the crop not only in the field but also during postharvest storage. Colletotrichum spp. are fungal pathogens that cause anthracnose. So far, 24 Colletotrichum species have been reported to cause chili anthracnose (de Silva et al. 2019; Diao et al. 2017; Liu et al. 2016; Mongkolporn and Taylor 2018). C. scovillei belongs to the $C$. acutatum species complex, which contains at least 34 species (Baroncelli et al. 2017; Bragança et al. 2016; Damm et al. 2012; De Silva et al. 2017, 2019; Jayawardena et al. 2016). In recent years, $C$. scovillei has been reported to cause anthracnose on chili in different countries (Caires et al. 2014; Kanto et al. 2014; Oo et al. 2017; Shin et al. 2019a). Liu et al. (2016) first isolated C. scovillei from pepper fruits in the Sichuan province of China and confirmed that $C$. scovillei was more pathogenic than six other Colletotrichum species (C. gloeosporioides, C. simense, C. fructicola, C. truncatum, $C$. brevisporum, and $C$. sichunensis). Other scholars subsequently isolated $C$. scovilleifrom chili fruits in different areas in China (Diao et al. 2017; Gao et al. 2017). Although C. scovillei is prevalent and causes severe damage to the chili crops in some countries (Kanto et al. 2014; Oo et al. 2017), there is no sufficient information on the genome of $C$. scovillei. Hence,

\footnotetext{
${ }^{\dagger}$ Corresponding authors: W. Wang; wlwang122@163.com and Z. Li; zhiqiangdo_771@163.com
}

*The $\boldsymbol{e}$-Xtra logo stands for "electronic extra" and indicates supplementary materials are published online.

The author(s) declare no conflict of interest.

Accepted for publication 28 September 2020.

Copyright $\odot 2021$ The Author(s). This is an open access article distributed under the CC BY-NC-ND 4.0 International license.

\section{$e-\mathrm{Xtra}^{*}$}

Funding

This work was supported by National Key Research and Development Program of China (2017YFD0201602), the Fund of Tianjin Academy of Agricultural Science (2018017), Tianjin Modern Agricultural Industry Technology System of Vegetable (ITTVRS2017010) and the Agricultural Science and Technology Innovation Program of the Chinese Academy of Agricultural Sciences.

\section{Keywords}

Colletotrichum scovillei, chili, genome, Nanopore 
Table 1. Genome assembly statistics of Colletotrichum scovillei TJNH1

\begin{tabular}{lc} 
Variables & Statistics \\
Genome assembly size $(\mathrm{Mb})$ & 52.03 \\
Number of scaffolds & 16 \\
Scaffold $N_{50}(\mathrm{bp})$ & $4,871,440$ \\
Largest scaffold $(\mathrm{bp})$ & $6,315,016$ \\
GC content $(\%)$ & 51.8 \\
BUSCO completeness & $98.62 \%$ \\
Number of genes & 13,419 \\
Number of signal peptides & 1,828 \\
Number of carbohydrate-active enzymes & 934 \\
Number of secreted proteins & 1,357 \\
\hline
\end{tabular}

sequencing the genome is an important step toward understanding the pathogenic mechanism of $C$. scovillei.

The strain TJNH1 was isolated from infected chili fruits from Tianjin City, China. Based on morphological characteristics and multigene phylogenetic analyses of ITS (Gardes and Bruns 1993; White et al. 1990), CAL (O'Donnell et al. 2000), CHS-1 (Carbone and Kohn 1999), ACT (Carbone and Kohn 1999), GAPDH (Guerber et al. 2003), and TUB2 (Woudenberg et al. 2009), TJNH1 was identified as C. scovillei. Genomic DNA was extracted from fresh fungal tissue samples using an E.Z.N.A. HP fungal DNA kit (Omega Bio-Tek). The Qubit and Thermo Scientific NanoDrop 2000 systems were utilized to evaluate DNA purity and content, and $0.35 \%$ agarose gel electrophoresis was carried out to test the DNA integrity. We recycled large segments of DNA using the BluePippin system and prepared a library using the ligation sequencing kit (SQK-LSK109; Oxford Nanopore Technologies) and NEB Next FFPE DNA repair mix kit. The high-quality library was sequenced on the ONT PromethION platform (ONT) using the ligation sequencing kit (SQKLSK109) and the flow cell priming kit (EXP-FLP002). Subreads that were of low quality and too short were removed, and the remaining subreads were used for genome assembly, using Canu v1.5 software (Koren et al. 2017). All settings were the default except for the following: genomeSize $=50 \mathrm{~m}$, rawErrorRate $=0.5$, correctedErrorRate $=0.12$, corOutCoverage $=100$. To obtain more accurate genome data, Illumina short reads obtained using the Nova-Seq 6000 system were used to correct the sequencing errors generated by Oxford Nanopore PromethION sequencing, using Pilon software (Walker et al. 2014) with default settings, except the mindepth and iteration parameters were set to 0.1 and 5 , respectively.

Thereafter, the completeness of the genome assembly was assessed using the BUSCO v3.0 program (Simão et al. 2015). This analysis indicated that the completeness of the TJNH1 genome assembly was $98.62 \%$ and there were 286 complete BUSCOs, two missing BUSCOs, two fragmented BUSCOs, and 290 total lineage BUSCOs. The genome had a total assembly length of $52,032,179 \mathrm{bp}$ and contained 16 scaffolds, with an $\mathrm{N}_{50}$ value of $4,871,440 \mathrm{bp}$ and a GC content of $51.8 \%$. The largest scaffold was $6,315,016 \mathrm{bp}$ and other characteristics of this genome were summarized in Table 1. The mitochondrial genome was identified by performing blast searches in the National Center for Biotechnology Information (NCBI) database. The sequences on scaffold 16 showed high similarity (99.99\%) to mitochondrial genes from Colletotrichum acutatum KC05, indicating that this scaffold is the mitochondrial genome, which is about $30.9 \mathrm{~kb}$ in size. The fungal genome repeat sequence database was constructed based on the principle of structure prediction and $a b$ initio prediction with the help of four software programs, namely, LTR_FINDER v1.05 (Xu and Wang 2007), MITE-Hunter (Han and Wessler 2010), RepeatScout v1.0.5 (Price et al. 2005), and PILER-DF v2.4 (Edgar and Myers 2005), was classfied using PASTEClassifier (Wicker et al. 2007), and was then merged with the Repbase (Jurka et al. 2005) database to generate the final repeat sequence database. The repeat sequences of the fungus were predicted based on the constructed repeat sequence database, using RepeatMasker v4.0.6 (Chen 2004) software, and a repetitive sequence of $1,325,448$ bp was obtained, with a repetitive sequence ratio of $2.55 \%$. By analyzing the repeats on both ends of each assembled scaffold, telomeric repeats

Vol. 34, No. 1, $2021 / 123$ 
(CCCTAA, which is the reverse complement of TTAGGG, the telomere repeat sequence reported for other Colletotrichum species [Liang et al. 2020]) were identified on the 5 ' ends of scaffolds 9 and 11 .

To better predict protein-coding genes, we obtained RNA-seq data for strain TJNH1 using the Nova-Seq 6000 system. The RNA-seq data were submitted to GenBank under accession number SRR12362003. We obtained $24,035,109$ read pairs with a final total length of 7,152,034,788 bp. The percentages of Q20 and Q30 bases were 98.05 and $94.65 \%$, respectively. The genome was annotated based on three different prediction strategies: ab initio prediction, homology-based prediction, and RNA-seq-based prediction. For RNA-seq-based prediction, the RNA-seq reads were aligned against our genome using HISAT2 (v2.0.4) (Pertea et al. 2016) to generate spliced alignments. Next, the RNA-seq reads were assembled using Trinity software (v2.1.1). Subsequently, the assembled transcripts were used for gene model prediction with TransDecoder v2.0 (B. J. Haas and A. Papanicolaou personal communication) and PASA v2.4.1 (Campbell et al. 2006), separately. The ab initio gene predictions were performed with Augustus v2.4 (Stanke and Waack 2003), Genscan (Burge and Karlin 1997), and GlimmerHMM v3.0.4 (Majoros et al. 2004), with parameters trained on the PASA predictions. For the homology-based prediction, three sequenced genomes of the Colletotrichum genus (C. higginsianum, C. fructicola, C. gloeosporioides) from NCBI were used to predict gene models with GeMoMa v1.3.1 (Keilwagen et al. 2016). Finally, RNA-seq-based gene models, ab initio-based gene models, and homology-based gene models were combined using EVidenceModeler (EVM) (Haas et al. 2008) to integrate a final gene set. For EVM, the default settings were used for all parameters except the weight file; we set the weight of the RNA-seq-based predictions to 20 , the weight of the homology based predictions to 10, and the weight of ab initio-based predictions to 1. For PASA the default settings were used, except for max IntronLength, which was set to 20,000. Default settings were used for all the other programs (i.e., HISAT2, Trinity, TransDecoder, Augustus v 2.4, Genscan, and GeMoMa). In total, 13,419 protein-coding genes were predicted. By analyzing the predicted protein sequences, 1,828 signal peptides were predicted, using SignalP 4.0 software (with default parameters) (Petersen et al. 2011). A total of 1,357 secreted proteins were predicted using EffectorP 2.0 software (Sperschneider et al. 2018). In the secretome, 258 proteins were identified as potential effectors, which may play vital roles in inactivating the host defense system. In addition, 2,957 transmembrane proteins were predicted by TMHMM software (with default parameters) (Krogh et al. 2001), and 934 carbohydrate-active enzymes, 137 transport proteins, and 4,473 pathogen-host interaction proteins were identified in searches of the CAZy, TCDB, and PHI databases ( $E$ value cutoff $=1 \mathrm{e}-05$ for all searches), respectively (Altschul et al. 1997; Cantarel et al. 2009; Eddy 1998; Saier et al. 2006; Winnenburg et al. 2006).

Moreover, we compared the strain TJNH1 assembly with other $C$. cautatum species complex assemblies, including those of $C$. fioriniae, C. nymphaeae, and $C$. salicis (Baroncelli et al. 2014, 2016). Based on these comparisons (Supplementary Table S1), the TJNH1 assembly is markedly better than the assemblies from other species in the species complex in terms of the number of scaffolds, scaffold $\mathrm{N}_{50}$, genome coverage, and sequencing technology. Our result provided a high-quality genome annotation reference of C. scovillei and an advanced research method on the genome sequencing of plant pathogen.

The genome described here is the first available for $C$. scovillei. This reference genome will provide insight into the pathogenic mechanism of $C$. scovillei and molecular plantpathogen interactions. The Nanopore and Illumina read data generated in this study have been submitted to GenBank under accession numbers SRR11060983 and SRR11091834, respectively. This whole-genome shotgun project has been deposited in GenBank under the accession number JAAJBS000000000. The version described in this paper is version JAAJBS010000000.

\section{Author-Recommended Internet Resource}

TransDecoder: http://transdecoder.github.io 


\section{Acknowledgments}

We are grateful to X. Shi and X. Xia from Institute of Plant Protection, Chinese Academy

of Agricultural Sciences for helpful suggestions for the manuscript.

\section{Literature Cited}

Altschul, S. F., Madden, T. L., Schäffer, A. A., Zhang, J., Zhang, Z., Miller, W., and Lipman, D. J. 1997. Gapped BLAST and PSI-BLAST: A new generation of protein database search programs. Nucleic Acids Res. 25: 3389-3402.

Baroncelli, R., Amby, D. B., Zapparata, A., Sarrocco, S., Vannacci, G., Le Floch, G., Harrison, R. J., Holub, E., Sukno, S. A., Sreenivasaprasad, S., and Thon, M. R. 2016. Gene family expansions and contractions are associated with host range in plant pathogens of the genus Colletotrichum. BMC Genomics 17:555.

Baroncelli, R., Sreenivasaprasad, S., Sukno, S. A., Thon, M. R., and Holub, E. 2014. Draft genome sequence of Colletotrichum acutatum Sensu Lato (Colletotrichum fioriniae). Genome Announc. 2:e00112-14.

Baroncelli, R., Talhinhas, P., Pensec, F., Sukno, S. A., Le Floch, G., and Thon, M. R. 2017. The Colletotrichum acutatum species complex as a model system to study evolution and host specialization in plant pathogens. Front. Microbiol. 8:2001.

Bragança, C. A. D., Damm, U., Baroncelli, R., Massola Júnior, N. S., and Crous, P. W. 2016. Species of the Colletotrichum acutatum complex associated with anthracnose diseases of fruit in Brazil. Fungal Biol. 120:547-561.

Burge, C., and Karlin, S. 1997. Prediction of complete gene structures in human genomic DNA. J. Mol. Biol. 268:78-94.

Caires, N. P., Pinho, D. B., Souza, J. S. C., Silva, M. A., Lisboa, D. O., Pereira, O. L., and Furtado, G. Q. 2014. First report of anthracnose on pepper fruit caused by Colletotrichum scovillei in Brazil. Plant Dis. 98:1437.

Campbell, M. A., Haas, B. J., Hamilton, J. P., Mount, S. M., and Buell, C. R. 2006. Comprehensive analysis of alternative splicing in rice and comparative analyses with Arabidopsis. BMC Genomics 7:327.

Cantarel, B. L., Coutinho, P. M., Rancurel, C., Bernard, T., Lombard, V., and Henrissat, B. 2009. The Carbohydrate-Active EnZymes database (CAZy): An expert resource for Glycogenomics. Nucleic Acids Res. 37 (Database):D233-D238.

Carbone, I., and Kohn, L. M. 1999. A method for designing primer sets for speciation studies in filamentous ascomycetes. Mycologia 91:553-556.

Chen, N. 2004. Using RepeatMasker to identify repetitive elements in genomic sequences. Curr. Protoc. Bioinformat. 5:4.10.1-4.10.14.

Damm, U., Cannon, P. F., Woudenberg, J. H. C., and Crous, P. W. 2012. The Colletotrichum acutatum species complex. Stud. Mycol. 73:37-113.

De Silva, D. D., Ades, P. K., Crous, P. W., and Taylor, P. W. J. 2017. Colletotrichum species associated with chili anthracnose in Australia. Plant Pathol. 66:254-267.

de Silva, D. D., Groenewald, J. Z., Crous, P. W., Ades, P. K., Nasruddin, A., Mongkolporn, O., and Taylor, P. W. J. 2019. Identification, prevalence and pathogenicity of Colletotrichum species causing anthracnose of Capsicum annuum in Asia. IMA Fungus 10:8.

Diao, Y. Z., Zhang, C., Liu, F., Wang, W. Z., Liu, L., Cai, L., and Liu, X. L. 2017. Colletotrichum species causing anthracnose disease of chili in China. Persoonia 38:20-37.

Eddy, S. R. 1998. Profile hidden Markov models. Bioinformatics 14:755-763.

Edgar, R. C., and Myers, E. W. 2005. PILER: Identification and classification of genomic repeats. Bioinformatics 21 (Suppl 1):i152-i158.

Gao, Y. Y., He, L. F., Li, B. X., Mu, W., Lin, J., and Liu, F. 2017. The potential of fludioxonil for anthracnose control on China chili fruit. Phytoparasitica 45:281-292.

Gardes, M., and Bruns, T. D. 1993. ITS primers with enhanced specificity for basidiomycetes--application to the identification of mycorrhizae and rusts. Mol. Ecol. 2:113-118.

Guerber, J. C., Liu, B., Correll, J. C., and Johnston, P. R. 2003. Characterization of diversity in Colletotrichum acutatum sensu lato by sequence analysis of two gene introns, mtDNA and intron RFLPs, and mating compatibility. Mycologia 95: 872-895.

Haas, B. J., Salzberg, S. L., Zhu, W., Pertea, M., Allen, J. E., Orvis, J., White, O., Buell, C. R., and Wortman, J. R. 2008. Automated eukaryotic gene structure annotation using EVidenceModeler and the Program to Assemble Spliced Alignments. Genome Biol. 9:R7.
Han, Y., and Wessler, S. R. 2010. MITE-Hunter: A program for discovering miniature inverted-repeat transposable elements from genomic sequences. Nucleic Acids Res. 38:e199.

Jayawardena, R. S., Hyde, K. D., Damm, U., Cai, L., Liu, M., Li, X. H., Zhang, W., Zhao, W. S., and Yan, J. Y. 2016. Notes on currently accepted species of Colletotrichum. Mycosphere 7:1192-1260.

Jurka, J., Kapitonov, V. V., Pavlicek, A., Klonowski, P., Kohany, O., and Walichiewicz, J. 2005. Repbase Update, a database of eukaryotic repetitive elements. Cytogenet. Genome Res. 110:462-467.

Kanto, T., Uematsu, S., Tsukamoto, T., Moriwaki, J., Yamagishi, N., Usami, T., and Sato, T. 2014. Anthracnose of sweet pepper caused by Colletotrichum scovillei in Japan. J. Gen. Plant Pathol. 80:73-78.

Keilwagen, J., Wenk, M., Erickson, J. L., Schattat, M. H., Garu, J., and Hartung, F. 2016. Using intron position conservation for homology-based gene prediction. Nucleic Acids Res. 44:e89.

Koren, S., Walenz, B. P., Berlin, K., Miller, J. R., Bergman, N. H., and Phillippy, A. M. 2017. Canu: Scalable and accurate long-read assembly via adaptive $k$-mer weighting and repeat separation. Genome Res. 27:722-736.

Krogh, A., Larsson, B., von Heijne, G., and Sonnhammer, E. L. L. 2001. Predicting transmembrane protein topology with a hidden Markov model: Application to complete genomes. J. Mol. Biol. 305:567-580.

Liang, X., Cao, M., Li, S., Kong, Y., Rollins, J. A., Zhang, R., and Sun, G. 2020. Highly contiguous genome resource of Colletotrichum fructicola generated using longread sequencing. Mol. Plant-Microbe Interact 33:790-793.

Liu, F., Tang, G., Zheng, X., Li, Y., Sun, X., Qi, X., Zhou, Y., Xu, J., Chen, H., Chang, X., Zhang, S., and Gong, G. 2016. Molecular and phenotypic characterization of Colletotrichum species associated with anthracnose disease in peppers from Sichuan Province, China. Sci. Rep. 6:32761.

Majoros, W. H., Pertea, M., and Salzberg, S. L. 2004. TigrScan and GlimmerHMM: Two open source ab initio eukaryotic gene-finders. Bioinformatics 20:2878-2879.

Mongkolporn, O., and Taylor, P. W. J. 2018. Chili anthracnose: Colletotrichum taxonomy and pathogenicity. Plant Pathol. 67:1255-1263.

O'Donnell, K., Nirenberg, H. I., Aoki, T., and Cigelnik, E. 2000. A multigene phylogeny of the Gibberella fujikuroi species complex: Detection of additional phylogenetically distinct species. Mycoscience 41:61-78.

Oo, M. M., Lim, G., Jang, H. A., and Oh, S. K. 2017. Characterization and pathogenicity of new record of anthracnose on various chili varieties caused by Colletotrichum scovillei in Korea. Mycobiology 45:184-191.

Pertea, M., Kim, D., Pertea, G. M., Leek, J. T., and Salzberg, S. L. 2016. Transcriptlevel expression analysis of RNA-seq experiments with HISAT, StringTie and Ballgown. Nat. Protoc. 11:1650-1667.

Petersen, T. N., Brunak, S., von Heijne, G., and Nielsen, H. 2011. SignalP 4.0: Discriminating signal peptides from transmembrane regions. Nat. Methods 8:785-786.

Price, A. L., Jones, N. C., and Pevzner, P. A. 2005. De novo identification of repeat families in large genomes. Bioinformatics 21 (Suppl 1):i351-i358.

Saier, M. H. J., Jr., Tran, C. V., and Barabote, R. D. 2006. TCDB: The Transporter Classification Database for membrane transport protein analyses and information. Nucleic Acids Res. 34:D181-D186.

Shin, J. H., Han, J. H., Park, H. H., Fu, T., and Kim, K. S. 2019. Colletotrichum scovillei to develop an applied genomics approach. Plant Pathol. J. 35: 575-584.

Simão, F. A., Waterhouse, R. M., loannidis, P., Kriventseva, E. V., and Zdobnov, E. M. 2015. BUSCO: Assessing genome assembly and annotation completeness with single-copy orthologs. Bioinformatics 31:3210-3212.

Sperschneider, J., Dodds, P. N., Gardiner, D. M., Singh, K. B., and Taylor, J. M. 2018. Improved prediction of fungal effector proteins from secretomes with EffectorP 2.0. Mol. Plant Pathol. 19:2094-2110.

Stanke, M., and Waack, S. 2003. Gene prediction with a hidden Markov model and a new intron submodel. Bioinformatics 19 (Suppl 2):ii215-ii225. 
Walker, B. J., Abeel, T., Shea, T., Priest, M., Abouelliel, A., Sakthikumar, S., Cuomo, C. A., Zeng, Q., Wortman, J., Young, S. K., and Earl, A. M. 2014. Pilon: An integrated tool for comprehensive microbial variant detection and genome assembly improvement. PLoS One 9:e112963.

White, T. J., Bruns, T., Lee, S., and Taylor, J. 1990. Amplifification and direct sequencing of fungal ribosomal RNA genes for phylogenetics. Pages 315-322 in: PCR Protocols: a guide to methods and applications. M. A. Innis, D. H. Gelfand, J. J. Sninsky, and T. J. White, eds. Academic Press, San Diego.

Wicker, T., Sabot, F., Hua-Van, A., Bennetzen, J. L., Capy, P., Chalhoub, B., Flavell, A., Leroy, P., Morgante, M., Panaud, O., Paux, E., Miguel, P. S., and Schulman,
A. H. 2007. A unified classification system for eukaryotic transposable elements. Nat. Rev. Genet. 8:973-982.

Winnenburg, R., Baldwin, T. K., Urban, M., Rawlings, C., Köhler, J., and HammondKosack, K. E. 2006. PHI-base: A new database for pathogen host interactions. Nucleic Acids Res. 34:459-464.

Woudenberg, J. H. C., Aveskamp, M. M., de Gruyter, J., Spiers, A. G., and Crous, P. W. 2009. Multiple Didymella teleomorphs are linked to the Phoma clematidina morphotype. Persoonia 22:56-62.

Xu, Z., and Wang, H. 2007. LTR_FINDER: An efficient tool for the prediction of fulllength LTR retrotransposons. Nucleic Acids Res. 35:W265-W268. 